\section{(A) Check for updates}

Cite this: Green Chem., 2021, 23, 546

Received 11th November 2020, Accepted 9th December 2020

DOI: $10.1039 / \mathrm{dOgc03818k}$

rsc.li/greenchem

\title{
Photochemical metal-free aerobic oxidation of thiols to disulfides $\uparrow$
}

\author{
Nikoleta Spiliopoulou and Christoforos G. Kokotos (DD *
}

Thiol oxidation to disulfides is an area of great importance in organic synthesis, both for synthetic and biological purposes. Herein, we report a mild, inexpensive and green photochemical approach for the synthesis of both symmetrical and non-symmetrical disulfides, using metal-free and environmentally friendly conditions. Utilizing phenylglyoxylic acid as the photoinitiator, common household bulbs as the light source and a simple inorganic salt as the additive, a versatile oxidation of thiols leading to products in excellent yields is described.

\section{Introduction}

Sulfur compounds, although usually associated with a foul smell, are considered non-toxic and can be found in a variety of natural products (Fig. 1). For example, sulforaphane is a key ingredient of the Brassicaceae family, that can be found in broccoli and cabbages that possesses anticancer activity, due to its isothiocyanate moiety. ${ }^{1}$ Among compounds containing sulfur, disulfides play a dominant role in biological systems, since they are fundamental factors in protein folding and oligomerization, as they stabilize the 3D structure and affect their biological function. ${ }^{2}$ Among the most common natural structures bearing a disulfide "bridge" is cystine, which is formed from the oxidation of cysteine, and insulin (Fig. 1). Disulfides are also important intermediates for many synthetic pathways and present various applications in agro-chemicals and pharmaceuticals. ${ }^{3,4}$ The latest global turmoil, regarding the pandemic caused by COVID-19, forced the scientific community to work intensively, in order to decode as fast as possible the structure and the function of the novel coronavirus. In this direction, researchers found that the spike protein of SARS-Cov-2019, which is the receptor-binding domain (RBD) to the ACE2 receptor of the host cell, consists of cysteine residues that form pairs with disulfide bonds. ${ }^{5}$ In fact, some of the latest studies confirm the importance of thiol-disulfide balance in the binding affinity of the spike protein to the ACE2 receptor. ${ }^{6}$ Furthermore, among the potential inhibitors of SARS-Cov-2019 protein are molecules that possess as a key unit

Laboratory of Organic Chemistry, Department of Chemistry,

National and Kapodistrian University of Athens, Panepistimiopolis, Athens 15771, Greece.E-mail: ckokotos@chem.uoa.gr

$\dagger$ Electronic supplementary information (ESI) available: Experimental data, ${ }^{1} \mathrm{H}$ and ${ }^{13} \mathrm{C}$ NMR, UV-Vis, fluorescence quenching studies and other mechanistic studies. See DOI: 10.1039/dogc03818k a non-symmetrical disulfide. ${ }^{5 e}$ These findings render disulfides, as moieties of great importance and synthetic interest.

Due to their importance, a plethora of synthetic methods to access disulfides has been reported, with most of them utilizing thiols as the starting materials. In many cases, the aerial oxidation of thiols can be catalyzed by metals or other frequently-used oxidation reagents, such as iodine, hydrogen peroxide, copper nanoparticles, bromine, $\mathrm{N}$-bromo-derivatives, nitrogen-containing oxidants, diethyl azodicarboxylate, sulfuryl chloride, peroxymonosulfate, peroxydisufate, miscellaneous reagents and chromates (Scheme 1A). ${ }^{7}$

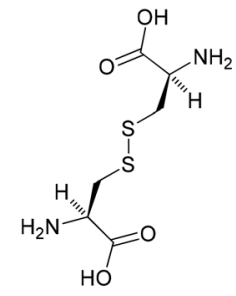

Cystine<smiles>C=CCSS/C=C\CS(=O)CC=C</smiles>

Anti-thrombotic
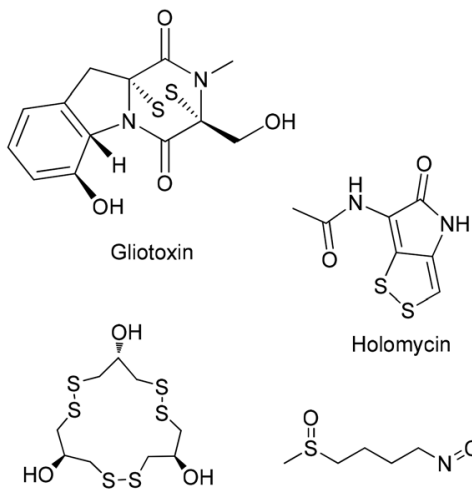

PTP1B inhibitor<smiles>C=[NH+]CCCCS(C)=O</smiles>

Sulforaphane

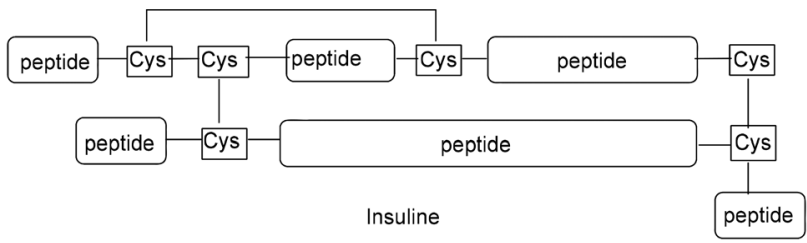

Fig. 1 Sulfur compounds of biological importance. 


\section{Previous Work}

A Aerial oxidation of thiols with different reagents 7

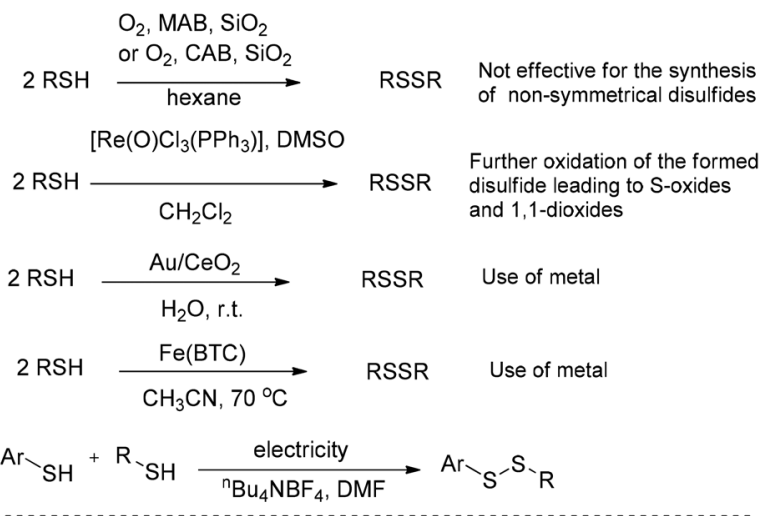

B Photocatalytic approaches with the use of metals ${ }^{10}$

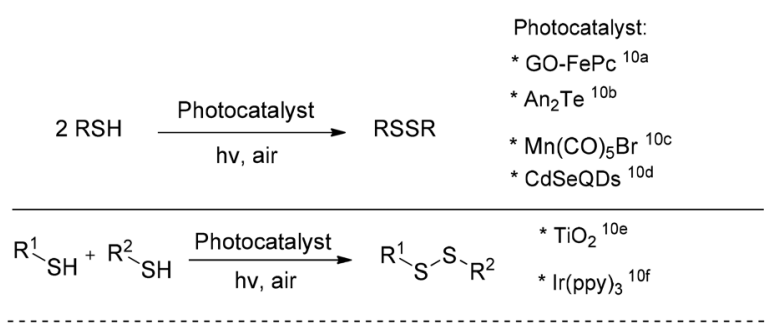

C Metal-free aerobic oxidation of thiols in continuous flow ${ }^{13}$ Noel and co-workers

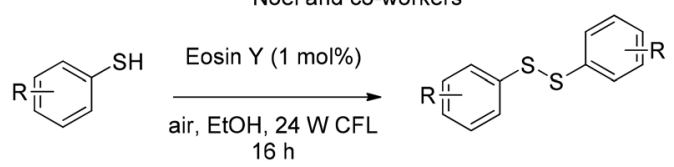

D This work

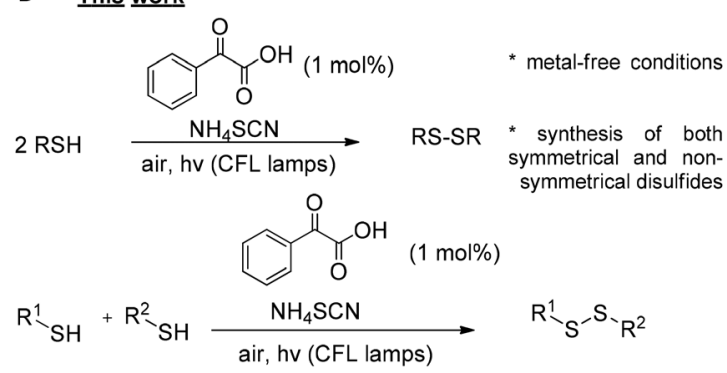

Scheme 1 Approaches for the synthesis of disulfides from thiols

An alternative approach for the oxidative coupling of thiols is the use of visible-light to achieve organic transformations. The increasing need for milder reactions conditions, cheaper and eco-friendlier oxidants led many researchers to discover new synthetic pathways based on photoredox catalysis, the use of visible light along with a photocatalyst to promote organic transformations. ${ }^{8,9}$ Basic feature in most photoredox reactions is the use of metal complexes as the photocatalyst. Photoredox catalysis also provided elegant approaches for the oxidation of thiols to disulfides (Scheme 1B). ${ }^{10}$ In all these cases, the authors postulate the importance of oxygen as the environmentally friendly and low-cost oxidant. A far cheaper approach and an alternative to photoredox catalysis is the introduction of photoorganocatalysis, the use of small organic molecules as photocatalysts. ${ }^{11,12}$ Exploring this promising field, Noel and co-workers introduced a continuous flow process, enabling a metal-free aerobic oxidation of thiols to disulfides, utilizing Eosin Y, an organic dye, as the photocatalyst and visible-light irradiation (Scheme 1C). ${ }^{13}$

Very recently, our group introduced in literature a photochemical protocol that is easy to operate employing cheap household bulbs as the source of irradiation. ${ }^{14}$ In an effort to expand this photochemical protocol, we envisaged the use of phenylglyoxylic acid as the photoinitiator for the oxidation of various thiols to disulfides (Scheme 1, bottom). This protocol is a green metal-free alternative to transition-metal photoredox catalysis.

\section{Results and discussion}

We initially investigated the oxidation of benzyl mercaptan (1a) (Scheme 2). A variety of commercially available photoinitiators $(\mathbf{3 a}-\mathbf{l})$ can promote the reaction. Phenylglyoxylic acid (3a) outperformed all others and proved the suitable photoinitiator, providing the product in quantitative yield (Scheme 2). The progress of the reaction was also monitored by GS-MS and the oxidation of thiol was completed after $7 \mathrm{~h}$. If the reaction was performed in the dark, or no catalyst was added, no reaction is taking place, constituting indispensable the use of both light and catalyst. Traces of product were also formed, when the reaction was performed under dark at $50{ }^{\circ} \mathrm{C}$.

Then, our interest was shifted towards the study of the reaction conditions (Table 1). ${ }^{15}$ After optimization, ${ }^{15}$ acetonitrile was found to be an excellent solvent (Table 1, entries 1-7). It has to be highlighted the important role of ammonium thio-

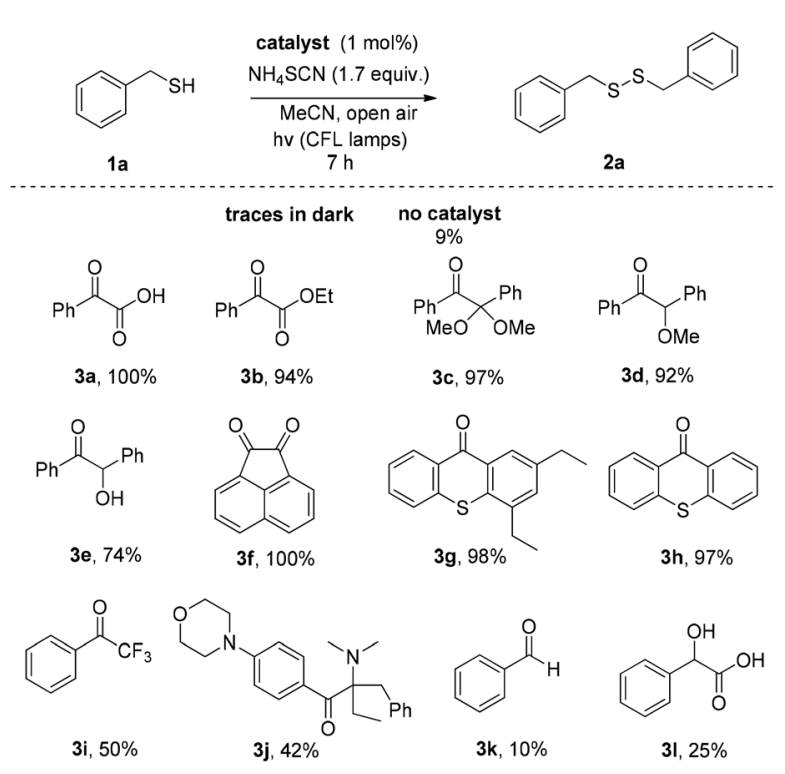

Scheme 2 Initiator screening for the photochemical synthesis of disulfide $2 \mathrm{a}$. 
Table 1 Optimization of the reaction conditions for the oxidation of thiols to disulfides

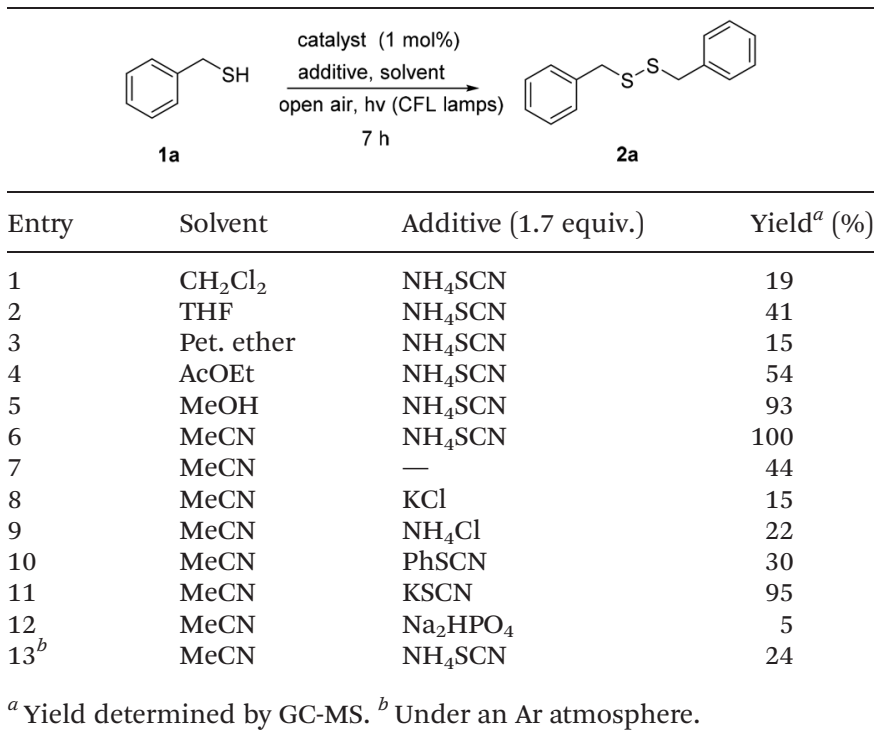

cyanate, since its absence led to diminished yields (Table 1, entry 7). Other additives were also tested (Table 1, entries $8-12)$. It seems that the presence of a salt containing either a ${ }^{-} \mathrm{SCN}$ or ${ }^{-} \mathrm{CN}$ is necessary, along with a $\mathrm{K}^{+}, \mathrm{Na}^{+}$or $\mathrm{NH}_{4}{ }^{+}$counterion. Under argon atmosphere, the reaction yield decreased (Table 1, entry 13). Thus, a green and sustainable protocol for the synthesis of disulfides from thiols, is introduced, where phenylglyoxylic acid is used as the initiator and cheap household bulbs can be employed as the light source.

Having established the optimum reaction conditions, we turned our attention in the exploration of the substrate scope of the reaction. First, a series of thiols were tested for the synthesis of symmetrical disulfides (Scheme 3). We realized that both aryl and alkyl thiols underwent disulfide formation in good to excellent yields. Various substitution patterns on the aromatic moiety were well tolerated (para-, ortho- and metasubstitution on electron withdrawing or donating groups), leading to products in mediocre to satisfactory yields (2a-o). The similar behaviour of different substrates under the optimized reaction conditions demonstrates the general applicability of this protocol, while this method allows us to encompass many different functional groups, such as $-\mathrm{NO}_{2},-\mathrm{COOH}$, protected $-\mathrm{NH}_{2},-\mathrm{OH}, \mathrm{RCOO}^{-}, \mathrm{RO}^{-}$or $-\mathrm{Cl}$. Apart from the success in para-, meta- and ortho-substituted substrates, it has also been possible to obtain successful results with aliphatic thiols or even with stereochemically hindered substrates. It has to be highlighted that in some cases, simple aqueous wash was enough to deliver the product with enough purity, not requiring further purification. ${ }^{15}$

Encouraged from these results, we anticipated that our method would be suitable for the synthesis of non-symmetrical disulfides (Scheme 4). In an effort to control the chemoselectivity of the reaction, a mixture of 2 equiv. of a thiol bearing polar groups and 1 equiv. of a simple thiol was treated

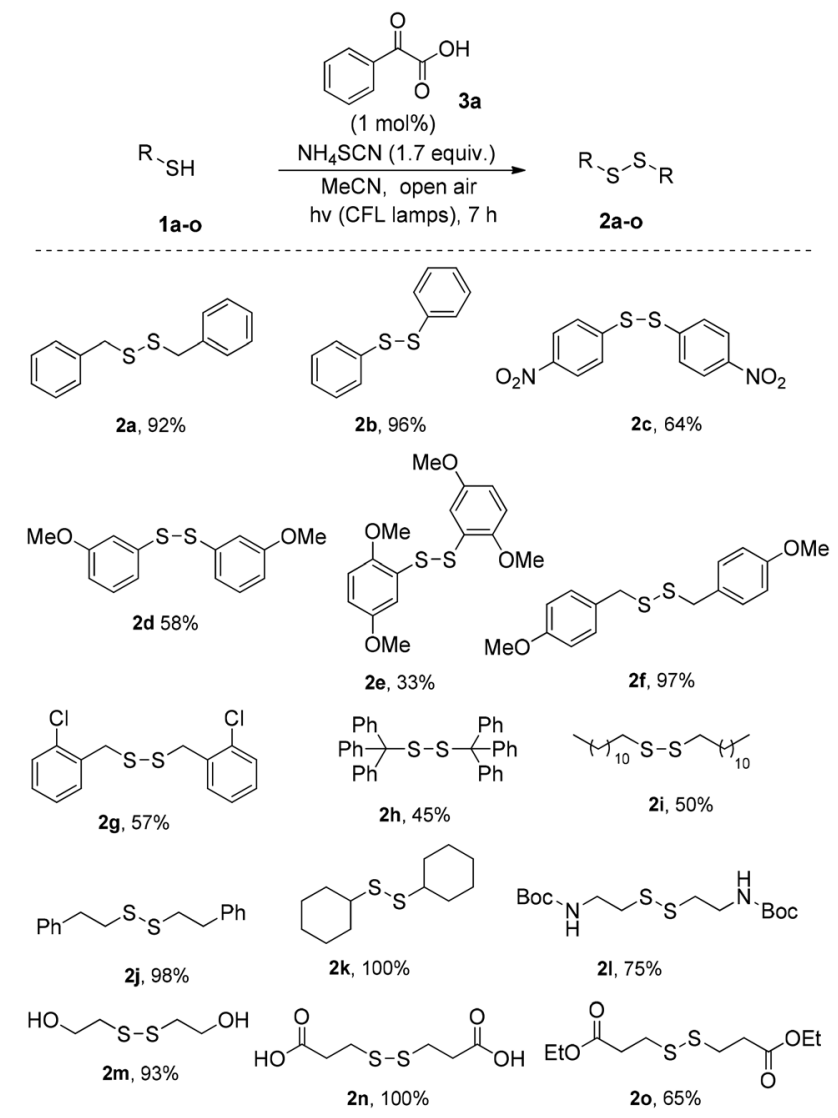

Scheme 3 Substrate scope of the photochemical synthesis of symmetrical disulfides.

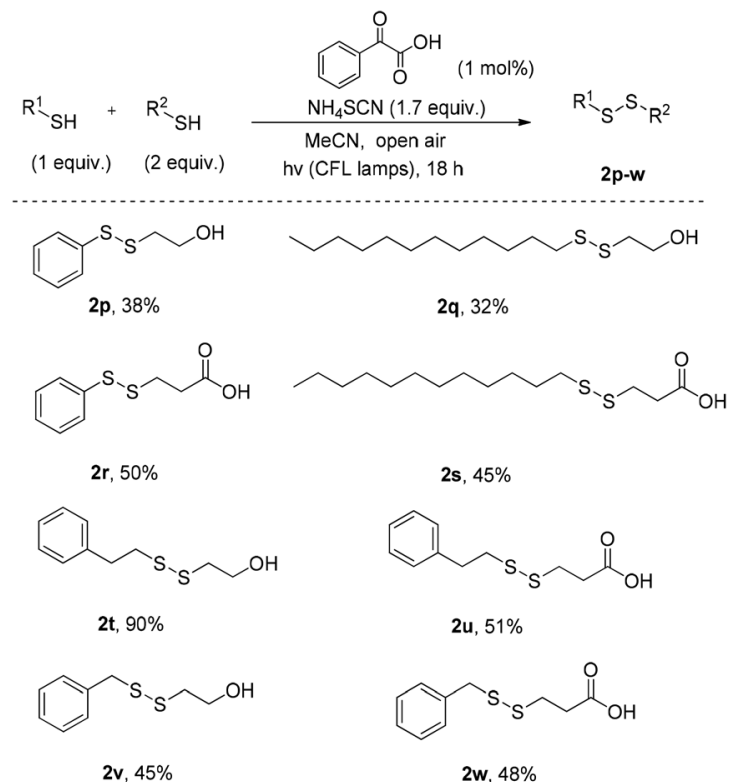

Scheme 4 Substrate scope of the photochemical synthesis of nonsymmetrical disulfides.

under the optimised reaction conditions. In this manner, the battle between the symmetrical and non-symmetrical products was reflected on the yields. We noticed that thiols that oxidised 
very well previously, do not present the same chemical behaviour as the half-part of a non-symmetrical disulfide. However, the fact that non-symmetrical disulfide formation is rarely described in literature and the metal-free conditions used, herein, constitute this green synthetic pathway very effective. Even low yields in some cases, can be admissible, in order to avoid the use of metals.

We then decided to decipher the reaction mechanism. Fluorescence quenching experiments with $\mathrm{PhCOCO}_{2} \mathrm{H}$ were initially performed. $^{15}$ Interestingly, the fluorescence of $\mathrm{PhCOCO}_{2} \mathrm{H}$ did not decrease, when an increasing amount of thiol or $\mathrm{NH}_{4} \mathrm{SCN}$ alone, were added. However, when a 1:1 mixture of thiol: $\mathrm{NH}_{4} \mathrm{SCN}$ was added, the fluorescence was decreased. ${ }^{15}$ This confirms the important role of ammonium thiocyanate and postulates that either $\mathrm{NH}_{4} \mathrm{SCN}$ forms a salt with $\mathrm{PhCOCO}_{2} \mathrm{H}$ and its fluorescence is decreased by thiol or that the thiol forms a salt with $\mathrm{NH}_{4} \mathrm{SCN}$, which decreases the fluorescence of $\mathrm{PhCOCO}_{2} \mathrm{H}$ or its salt. Then, UV-Vis were performed. ${ }^{15}$ The association of an electron rich molecule with an electron poor compound can lead to the formation of a new aggregate, called electron donor-acceptor (EDA) complex. In some cases, upon addition of the two components of the EDA complex, an increase in the UV absorbance of the mixture is observed. In our case, upon mixing the various reaction components, no remarkable increase in the UV absorbance was observed, rejecting the possibility of an EDA complex formation.

The reaction was also probed by the use of NMR spectroscopy. Phenylglyoxylic acid photodecomposed slowly to benzaldehyde, when irradiated alone in MeCN, obviously via a benzoyl radical. ${ }^{15}$ This photodecomposition was faster and more in quantity, when $\mathrm{NH}_{4} \mathrm{SCN}$ was present, which shows that the salt of $\mathrm{PhCOCO}_{2} \mathrm{H}$ with $\mathrm{NH}_{4} \mathrm{SCN}$, photodecomposes faster to benzaldehyde than $\mathrm{PhCOCOOH}$ alone. Salt formation between thiol and $\mathrm{NH}_{4} \mathrm{SCN}$ was also evident. Finally, in the reaction mixture, the photodecomposition to benzaldehyde was also observed. ${ }^{15}$ We also performed a number of mechanistic experiments with a number of probes (Table 2). Obviously, this is a radical process (Table 2, entries 1 and 2). Interestingly, the use of $\mathrm{CuCl}_{2}$ (Table 2, entry 3 ) verified the fluorescence quenching experiments that a SET mechanism is contributing in a minor extend (if any) for the reaction outcome. Finally, oxygen species are taking part in the reaction (Table 2, entries 4-7).

In 2015, Cismesia and Yoon introduced the quantum yield measurement as a mechanistic tool. ${ }^{16}$ A closed photocatalytic system, which lacks chain propagation, exhibits a maximum theoretical quantum yield of $\Phi=1$. Open chain processes in principle can provide multiple equivalents of product from each photon absorbed, therefore the quantum yield of a chain reaction is $\Phi \gg 1$. We calculated the quantum yield of the reaction $(\Phi=38)$, indicating a chain propagation mechanism. ${ }^{15}$

Based on the above experiments, a plausible reaction mechanism can be proposed (Scheme 5). Upon irradiation, phenylglyoxylic acid in MeCN is slowly photodecomposed to benzaldehyde via benzoyl radical I (Scheme 5, top left). If
Table 2 Mechanistic studies on the photochemical oxidation of benzyl mercaptan

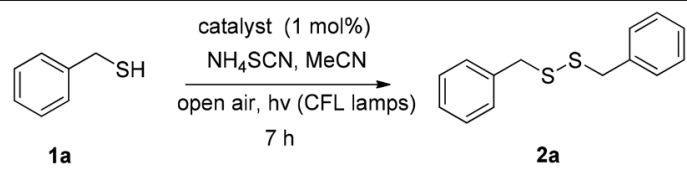

\begin{tabular}{lllc}
\hline Entry & Quencher (equiv.) & Notes & $\begin{array}{c}\text { Yield }^{a} \\
(\%)\end{array}$ \\
\hline 1 & BHT (1.0) & Radical scavenger & 0 \\
2 & TEMPO (1.0) & Radical scavenger & 0 \\
3 & CuCl $_{2}(1.0)$ & Electron scavenger & 87 \\
4 & DABCO (1.0) $_{5}$ & Singlet oxygen scavenger & 30 \\
6 & NaN $_{3}(1.0)$ & Singlet oxygen scavenger & 10 \\
7 & Benzoquinone & Superoxide radical anion & 37 \\
& $(1.0)$ & Scavenger & 24
\end{tabular}

${ }^{a}$ Yield determined by GC-MS.
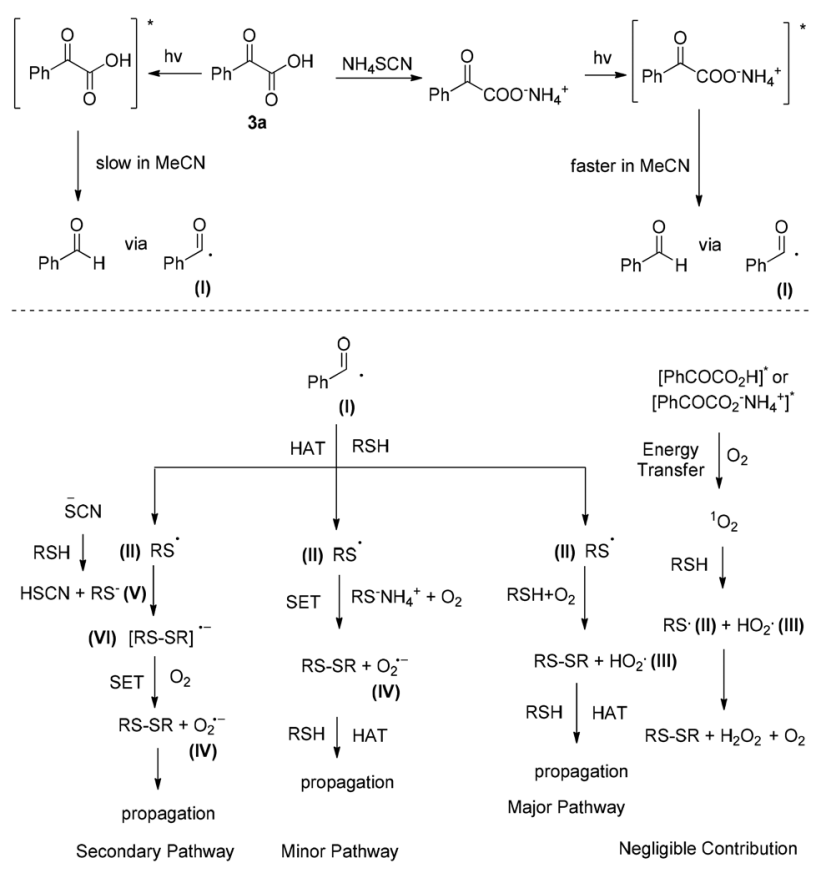

Scheme 5 Proposed reaction mechanism for the photochemical aerobic oxidation of thiols to disulfides using phenylglyoxylic acid as the photoinitiator.

$\mathrm{NH}_{4} \mathrm{SCN}$ is present, salt formation with $\mathrm{PhCOCO}_{2} \mathrm{H}$ leads to a faster photodecomposition to benzaldehyde via benzoyl radical I (Scheme 5, top right). Then, one can envisage a number of potential pathways that can be followed (Scheme 5, bottom). There is a possibility that excited $\mathrm{PhCOCO}_{2} \mathrm{H}$ or its salt can lead to singlet oxygen generation via energy transfer, which is known in literature to interact with thiols and initiate disulfide formation (Scheme 5, bottom far right). ${ }^{10}$ However, $\mathrm{PhCOCO}_{2} \mathrm{H}$ is a poor singlet oxygen generator, according to our previous studies, ${ }^{14 l}$ and thus this pathway must not be very productive in this method. On the other hand, benzoyl radical 
I, generated either by excited $\mathrm{PhCOCOOH}$ or the salt of PhCOCOOH with $\mathrm{NH}_{4} \mathrm{SCN}$, can initiate a hydrogen atom transfer (HAT) with the thiol, leading to thiyl radical II (Scheme 5, bottom right). Then, via reaction with another thiol and oxygen, disulfide is formed, along with $\mathrm{HO}_{2}$. (III). III can propagate the reaction via HAT with the thiol. This is probably the major pathway followed in our method, that can account for the reactivity without the additive as well. Similarly, thiyl radical II can react with the salt of thiol and $\mathrm{NH}_{4} \mathrm{SCN}$, in the presence of oxygen, and via a less likely SET (single electron transfer) affords the product and superoxide anion IV (Scheme 5, bottom left). Superoxide anion can propagate the reaction via HAT with the thiol. This is probably a minor pathway in our method, since the use of an electron scavenger reduced the yield of the methodology only marginally. Finally, salt formation between thiol and $\mathrm{NH}_{4} \mathrm{SCN}$ leads to $\mathrm{RS}^{-}$(V) (Scheme 5, bottom far left). This reacts with II leading to VI. ${ }^{13}$ This is already postulated in literature that reacts with oxygen via a SET event, leading to product and superoxide radical IV, which as previously, can propagate the reaction.

\section{Conclusions}

In conclusion, a simple, cheap and environmentally friendly photochemical protocol was developed and successfully applied to the oxidation of aryl and alkyl thiols to symmetrical and non-symmetrical disulfides. Bypassing the need for transition metal complexes or organic dyes, and thermal (photo) initiators, this method relies on a small organic molecule and cheap household bulbs. Phenylglyoxylic acid can be employed in a very low catalyst loading ( $1 \mathrm{~mol} \%$ ), leading to products in good to excellent yields. The mechanism of the reaction was also studied.

\section{Experimental}

\section{General procedure for the synthesis of disulfides}

In a glass vial containing phenylglyoxylic acid (0.8 mg, $0.005 \mathrm{mmol}$ ) and ammonium thiocyanate (65 $\mathrm{mg}, 0.85 \mathrm{mmol})$ in acetonitrile $(2 \mathrm{~mL})$, thiol $(0.50 \mathrm{mmol})$ was added. The reaction mixture was irradiated on open air with $2 \times 85$ W household bulbs with vigorous stirring for $7 \mathrm{~h}$. The desired product was isolated either after dilution with $\mathrm{CH}_{2} \mathrm{Cl}_{2}(5 \mathrm{~mL})$, wash with $10 \%$ aq. $\mathrm{NaHCO}_{3}(2 \times 5 \mathrm{~mL})$ and the organic layer was dried over $\mathrm{Na}_{2} \mathrm{SO}_{4}$ and the solvent was removed in vacuo or after purification by column chromatography.

\section{Author contributions}

Conceptualization: C. G. K.; reaction optimization, substrate scope and compound characterization: N. S.; mechanistic studies: N. S. and C. G. K.; writing original draft: N. S. and C. G. K.; writing, reviewing and editing: C. G. K.; supervision and project administration: C. G. K.; funding acquisition: N. S. and C. G. K.

\section{Conflicts of interest}

The authors declare no conflicts.

\section{Acknowledgements}

The authors gratefully acknowledge the Hellenic Foundation for Research and Innovation (HFRI) for financial support through a grant, which is financed by $1^{\text {st }}$ Call for H.F.R.I. Research Projects to Support Faculty Members \& Researchers and the procurement of high-cost research equipment grant (grant number 655). N.S. would like to thank the Hellenic Foundation for Research and Innovation (HFRI) for financial support through a doctoral by the Hellenic Foundation for Research and Innovation (HFRI) under PhD Fellowship grant (Fellowship Number: 721). Also, COST Action C-H Activation in Organic Synthesis (CHAOS) CA15106 is acknowledged for helpful discussions.

\section{Notes and references}

1 M. G. Kokotou, P. K. Revelou, C. Pappas and V. Constantinou-Kokotou, Food Chem., 2017, 237, 566-573.

2 (a) E. Gross, C. S. Sevier, A. Vala, C. A. Kaiser and D. Fass, Nat. Struct. Mol. Biol., 2002, 9, 61-67; (b) J. R. Winther and C. Thorpe, Biochim. Biophys. Acta, 2014, 1840, 838-846; (c) M. Gongora-Bernitez, J. Tulla-Puche and F. Albericio, Chem. Rev., 2014, 114, 901-926; (d) S. Patai, The Chemistry of the Thiol Group, John Willey and Sons, 1974, pp. 113-119.

3 For a review, see: (a) B. Mandal and B. Basu, $R S C A d v$, 2014, 4, 13854-13881. For some recent examples on the use of disulfides in synthesis, see: (b) V. Pace, A. Pelosi, D. Antermite, O. Rosati, M. Curini and W. Holzer, Chem. Commun., 2016, 52, 2639-2642; (c) L. Lelo, V. Pillari, N. Gajic, W. Holzer and V. Pace, Chem. Commun., 2020, 56, 12395-12398.

4 (a) E. Block, S. Ahmad, M. K. Jain, R. W. Crecely, R. ApitzCastro and M. R. Cruz, J. Am. Chem. Soc., 1984, 106, 82958296; (b) J.-X. Gong, X. Shen, L.-G. Yao, H. Jiang, K. Krohn and Y.-W. Guo, Org. Lett., 2007, 9, 1715-1716.

5 (a) I. M. Ibrahim, D. H. Abdelmalek, M. E. Elshahat and A. A. Elfiky, J. Infect., 2020, 80, 554-562; (b) J. Yu, S. Qiao, R. Guo and X. Wang, Nat. Commun., 2020, 11, 3070-3081; (c) J. Lan, J. Ge, J. Yu, S. Shan, H. Zhou, S. Fan, Q. Zhang, X. Shi, Q. Wang, L. Zhang and X. Wang, Nature, 2020, 581, 215-220; (d) D. Wrapp, N. Wang, K. S. Corbett, J. A. Goldsmith, C.-L. Hsieh, O. Abiona, B. S. Graham and J. S. McLellan, Science, 2020, 367, 1260-1263; (e) Z. Jin, X. Du, Y. Xu, Y. Deng, M. Liu, Y. Zhao, B. Zhang, X. Li, L. Zhang, C. Peng, Y. Duan, J. Yu, L. Wang, K. Yang, F. Liu, 
R. Jiang, X. Yang, T. You, X. Liu, X. Yang, F. Bai, H. Liu, X. Liu, L. W. Guddat, W. Xu, G. Xiao, C. Qin, Z. Shi, H. Jiang, Z. Rao and H. Yang, Nature, 2020, 582, 289-293.

6 S. Hati and S. Bhattacharyya, ACS Omega, 2020, 5(26), 16292-16298.

7 For a review, see: (a) D. Witt, Synthesis, 2008, 2491-2509. For a recent contribution, see: (b) P. Huang, P. Wang, S. Tang, Z. Fu and A. Lei, Angew. Chem., Int. Ed., 2018, 57, 8115-8119.

8 For selected reviews, see: (a) C. K. Prier, D. A. Rankic and D. W. C. MacMillan, Chem. Rev., 2013, 113, 5322-5363; (b) K. L. Scubi, T. R. Blum and T. P. Yoon, Chem. Rev., 2016, 116, 10035-10074; (c) M. D. Kärkäs, J. A. Porco Jr. and C. R. J. Stephenson, Chem. Rev., 2016, 116, 9683-9747; (d) D. Cambie, C. Bottecchia, N. J. W. Straathof, V. Hessel and T. Noel, Chem. Rev., 2016, 116, 10276-10341; (e) F. Strieth-Kalthoff, M. J. James, M. Teders, L. Pitzera and F. Glorius, Chem. Soc. Rev., 2018, 47, 7190-7202; (f) L. Marzo, S. K. Pagire, O. Reiser and B. König, Angew. Chem., Int. Ed., 2018, 57, 10034-10072.

9 For selected examples, see: (a) M. Neumann, S. Fuldner, B. Konig and K. Zeitler, Angew. Chem., Int. Ed., 2011, 50, 951-954; (b) F. Burg, M. Gicquel, S. Breitenlechner, A. Pöthig and T. Bach, Angew. Chem., Int. Ed., 2018, 57, 2953-2957; (c) E. Speckmeier, P. J. W. Fuchs and K. Zeitler, Chem. Sci., 2018, 9, 7096-7103; (d) T. Patra, S. Mukherjee, J. Ma, F. Strieth-Kalthoff and F. Glorius, Angew. Chem., Int. Ed., 2019, 58, 10514-10520; (e) L. Capaldo, D. Merli, M. Fagnoni and D. Ravelli, ACS Catal., 2019, 9, 3054-3058.

10 (a) P. Kumar, G. Singh, D. Tripathi and S. L. Jain, RSC Adv., 2014, 4, 50331-50337; (b) M. Oba, K. Tanak, K. Nishiyama and W. Ando, J. Org. Chem., 2011, 76, 4173-4177; (c) K. Y. Desmond Tan, G. F. Teng and W. Y. Fan, Organometallics, 2011, 30, 4136-4143; (d) X.-B. Li, Z.-J. Li, Y.-J. Gao, Q.-Y. Meng, S. Yu, R. G. Weiss, C.-H. Tung and L.-Z. Wu, Angew. Chem., Int. Ed., 2014, 53, 2085-2089; (e) C. Bottecchia, N. Erdmann, P. M. Tijssen, L. G. Milroy, L. Brunsveld, V. Hessel and T. Noël, ChemSusChem, 2016, 9, 1781-1785; $(f)$ D. H. Dethe, A. Srivastava, B. D. Dherange and B. V. Kumar, Adv. Synth. Catal., 2018, 360, 3020-3025.

11 For selective reviews see: (a) M. Fagnoni, D. Dondi, D. Ravelli and A. Albini, Chem. Rev., 2007, 107, 2722756; (b) D. Ravelli, S. Protti and M. Fagnoni, Chem. Rev., 2016, 116, 9850-9913; (c) D. Ravelli, S. Protti and M. Fagnoni, Acc. Chem. Res., 2016, 49, 2232-2242; (d) N. A. Romero and D. A. Nicewicz, Chem. Rev., 2016, 116, 10075-11116; (e) I. K. Sideri, E. Voutyritsa and C. G. Kokotos, Org. Biomol. Chem., 2018, 16, 4596-4614; (f) M. A. Theodoropoulou,
N. F. Nikitas and C. G. Kokotos, Beilstein J. Org. Chem., 2020, 16, 833-857.

12 For selected example see: (a) J. Grandjean and D. A. Nicewicz, Angew. Chem., Int. Ed., 2013, 52, 3967-3971; (b) I. Ghosh, T. Ghosh, J. I. Bardagi and B. König, Science, 2014, 346, 725-728; (c) T. M. Nguyen, N. Manohar and D. A. Nicewicz, Angew. Chem., Int. Ed., 2014, 53, 6198-6201; (d) E. Arceo, I. D. Jurberg, A. Álvarez-Fernández and P. Melchiorre, Nat. Chem., 2013, 5, 750-756; (e) E. Arceo, E. Montroni and P. Melchiorre, Angew. Chem., Int. Ed., 2014, 53, 12064-12068; (f) J. J. Murphy, D. Bastida, S. Paria, M. Fagnoni and P. Melchiorre, Nature, 2016, 532, 218-222; $(g)$ L. Pitzer, F. Sandfort, F. Strieth-Kalthoff and F. Glorius, J. Am. Chem. Soc., 2017, 139, 13652-13655.

13 A. Talla, B. Driessen, N. J. W. Straathof, L. G. Milroy, L. Brunsveld, V. Hessel and T. Noel, Adv. Synth. Catal., 2015, 357, 2180-2186.

14 For PhCOCOOH-mediated processes, see: (a) G. N. Papadopoulos, D. Limnios and C. G. Kokotos, Chem. - Eur. J., 2014, 20, 13811-13814; (b) G. N. Papadopoulos and C. G. Kokotos, Chem. - Eur. J., 2016, 22, 6964-6967; (c) G. N. Papadopoulos and C. G. Kokotos, J. Org. Chem., 2016, 81, 7023-7028; (d) D. Limnios and C. G. Kokotos, Adv. Synth. Catal., 2017, 359, 323-328; (e) N. Kaplaneris, A. Bisticha, G. N. Papadopoulos, D. Limnios and C. G. Kokotos, Green Chem., 2017, 19, 4451-4456; ( $f$ ) G. N. Papadopoulos, E. Voutyritsa, N. Kaplaneris and C. G. Kokotos, Chem. Eur. J., 2018, 24, 1726-1731; (g) E. Voutyritsa and C. G. Kokotos, Angew. Chem., Int. Ed., 2020, 59, 1735-1741; (h) G. N. Papadopoulos, M. G. Kokotou, N. Spiliopoulou, N. F. Nikitas, E. Voutyritsa, D. I. Tzaras, N. Kaplaneris and C. G. Kokotos, ChemSusChem, 2020, 13, 5934-5944; (i) E. Voutyritsa, M. Garreau, M. G. Kokotou, I. Triandafillidi, J. Waser and C. G. Kokotos, Chem. - Eur. J., 2020, 26, 14453-14460. For other photoinitiators, see: (j) I. K. Sideri, E. Voutyritsa and C. G. Kokotos, ChemSusChem, 2019, 12, 4194-4201; (k) N. F. Nikitas, I. Triandafillidi and C. G. Kokotos, Green Chem., 2019, 21, 669-674; (l) N. F. Nikitas, D. I. Tzaras, I. Triandafillidi and C. G. Kokotos, Green Chem., 2020, 22, 471-477; (m) N. Spiliopoulou, N. F. Nikitas and C. G. Kokotos, Green Chem., 2020, 22, 3539-3545.

15 For full reaction conditions, optimization and mechanistic studies, see ESI. $\dagger$

16 M. A. Cismesia and T. P. Yoon, Chem. Sci., 2015, 6, 54265434. 